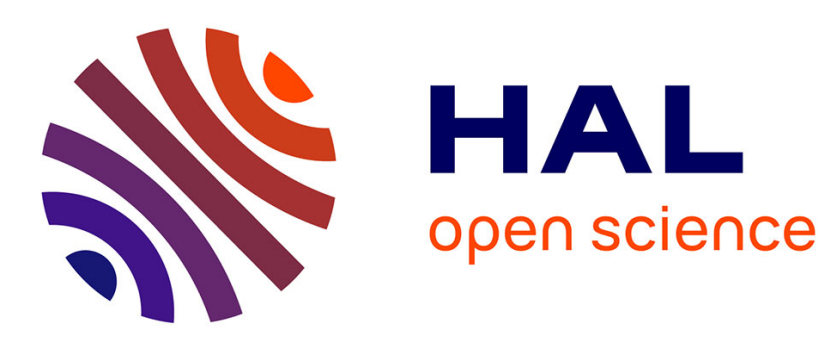

\title{
Measurement of the extent of strain relief in InGaAs layers grown under tensile strain on $\operatorname{InP}(100)$ substrates
}

P. Maigné, M. Gendry, T. Venet, Y. Tahri, G. Hollinger

\section{To cite this version:}

P. Maigné, M. Gendry, T. Venet, Y. Tahri, G. Hollinger. Measurement of the extent of strain relief in InGaAs layers grown under tensile strain on $\mathrm{InP}(100)$ substrates. Applied Physics Letters, 1996, 69 (5), pp.682-684. 10.1063/1.117805 . hal-02111832

\section{HAL Id: hal-02111832 \\ https://hal.science/hal-02111832}

Submitted on 26 Apr 2019

HAL is a multi-disciplinary open access archive for the deposit and dissemination of scientific research documents, whether they are published or not. The documents may come from teaching and research institutions in France or abroad, or from public or private research centers.
L'archive ouverte pluridisciplinaire HAL, est destinée au dépôt et à la diffusion de documents scientifiques de niveau recherche, publiés ou non, émanant des établissements d'enseignement et de recherche français ou étrangers, des laboratoires publics ou privés. 


\section{Measurement of the extent of strain relief in InGaAs layers grown under tensile strain on InP(100) substrates}

Cite as: Appl. Phys. Lett. 69, 682 (1996); https://doi.org/10.1063/1.117805

Submitted: 05 March 1996 . Accepted: 21 May 1996 . Published Online: 04 June 1998

P. Maigné, M. Gendry, T. Venet, Y. Tahri, and G. Hollinger

\section{ARTICLES YOU MAY BE INTERESTED IN}

Strain relaxation in high Ge content $\mathrm{SiGe}$ layers deposited on $\mathrm{Si}$

Journal of Applied Physics 107, 063504 (2010); https://doi.org/10.1063/1.3327435

Calculation of critical layer thickness versus lattice mismatch for $\mathrm{Ge}_{\chi} \mathrm{Si}_{1-\chi} / \mathrm{Si}$ strained-layer heterostructures

Applied Physics Letters 47, 322 (1985); https://doi.org/10.1063/1.96206

Tensile and compressive strain relief in $\operatorname{In}_{x} \mathrm{Ga}_{1-x}$ As epilayers grown on InP probed by Raman scattering

Journal of Applied Physics 82, 803 (1997); https://doi.org/10.1063/1.365775

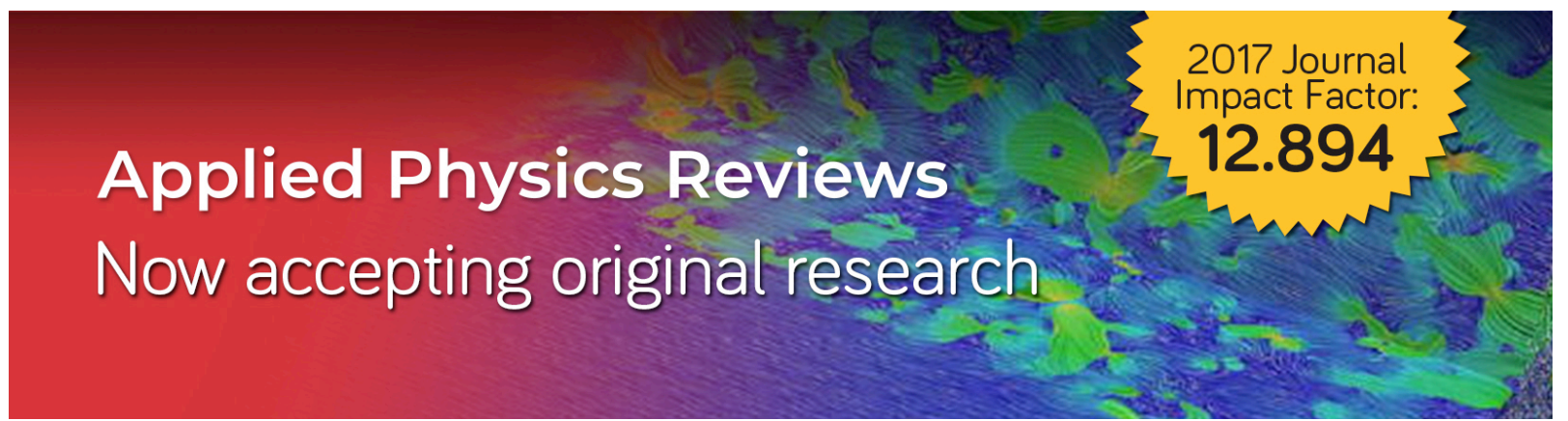




\title{
Measurement of the extent of strain relief in InGaAs layers grown under tensile strain on $\operatorname{In} P(100)$ substrates
}

\author{
P. Maignéa) \\ Communications Research Centre, P. O. Box 11490, Station H, Ottawa, Ontario K2H 8S2, Canada \\ M. Gendry, T. Venet, Y. Tahri, ${ }^{\text {b) }}$ and G. Hollinger \\ Laboratoire d'Electronique, L.E.A.M.E., URA-CNRS 848, Ecole Centrale de Lyon, 36 Avenue de Collongue, \\ 69131 Ecully, Cedex France
}

(Received 5 March 1996; accepted for publication 21 May 1996)

\begin{abstract}
High resolution $x$-ray diffraction has been used to investigate the structural properties of $\mathrm{In}_{x} \mathrm{Ga}_{1-x}$ As epitaxial layers grown under tension on $\operatorname{InP}(100)$ substrates. The nominal indium composition $(x=0.42)$ corresponds to a small lattice mismatch and a two dimensional growth mode. We have also included for comparison two samples grown under compression covering the mostly strained and the mostly relaxed regimes. Our results show that the residual strain and the asymmetry in strain relaxation along $\langle 011\rangle$ directions are always larger for layers under tension. This can be explained by the difference in dislocation glide velocity induced by a different indium content, by the dissociation of perfect dislocations and partially by the difference in thermal expansion coefficients between substrate and epilayer. The larger asymmetry in strain relaxation for tensile strain layers is interpreted by the existence of microcracks aligned in the [011] direction. (C) 1996 American Institute of Physics. [S0003-6951(96)02031-1]
\end{abstract}

It is now well established that when epitaxial layers under low compressive strain exceed their critical layer thickness an array of misfit dislocations is formed at the epilayersubstrate interface. This strain relaxation mechanism has been extensively studied with a variety of structural characterization techniques, in particular in the InGaAs/GaAs system. ${ }^{1-6}$ For layers under tensile strain, such as the InAlSb/InSb system, it has been recently suggested ${ }^{7}$ that the relaxation mechanism might be different since the residual strain is significantly larger in equivalent layer structures. In addition, the experimental critical layer thickness for the formation of stress releasing defects was found to be five times larger than the critical layer thickness for the formation of misfit dislocations. However, a quantitative comparison between the two systems is not necessarily appropriate because the materials exhibit different physico-chemical, mechanical, and thermal properties.

The $\mathrm{In}_{x} \mathrm{Ga}_{1-x} \mathrm{As} / \mathrm{InP}$ system is of particular interest for the direct quantitative comparison of the relaxation processes involved in tensile and compressive strain systems. Depending upon the indium composition, $x$, the epitaxial layers display a negative $(x<0.53)$ or a positive $(x>0.53)$ lattice mismatch. This system has already been studied in some detail using transmission electron microscopy (TEM) ${ }^{8-12}$ reflection high energy electron diffraction (RHEED), ${ }^{9,12}$ x-ray diffraction (XRD), ${ }^{8,11}$ optical microscopy, ${ }^{8,11}$ and atomic force microscopy (AFM). ${ }^{12,13}$ For low-mismatch layers, AFM and optical microscopy studies showed drastically different surfaces morphologies according to the type of misfit: a crosshatch pattern for layers under compression and a pattern characterized by a high density of lines almost exclusively aligned along the [0-11] direction for layers under tension.

\footnotetext{
${ }^{\text {a)} E l e c t r o n i c ~ m a i l: ~ p a s c a l . m a i g n e @ c r c . d o c . c a ~}$

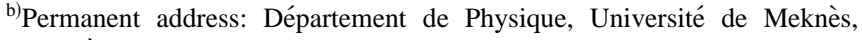
Meknès, Maroc.
}

In addition, while $60^{\circ}$ type dislocations are usually the main defects observed in partially relaxed layers under low compressive strain, TEM investigations have shown that, in partially relaxed layers under tensile strain, $90^{\circ}$ and $30^{\circ}$ partial dislocations with stacking faults and microtwins, as well as cracks are also present. Therefore, structural studies indicate that two different mechanisms take place according to the type of mismatch. However, it is not clear, at the present time, to what extent the two mechanisms are different and in particular which type of defect is mostly responsible for the relaxation of the elastic strain in the tensile regime. In order to clarify these points, we have studied the residual strain in both compressive and tensile strained InGaAs layers. To our knowledge, it is the first quantitative comparison of the residual strain done for this system.

Using a RIBER 2300 molecular beam epitaxy system, a series of four samples was grown under tension with a nominal indium composition $x=0.42$, corresponding to a nominal lattice mismatch $f$ of about $-8 \times 10^{-3}$. The layer thicknesses were $200,500,700 \mathrm{~nm}$, and $1 \mu \mathrm{m}$, respectively. In addition, we have included for comparison two samples grown under compression with a nominal indium composition of $x=0.65$ and with layer thicknesses of 80 and $520 \mathrm{~nm}$, respectively. This indium composition corresponds to the same absolute value of the lattice mismatch of layers under tensile stress. In all cases, the epitaxial growth proceeds layer by layer with a two-dimensional (2D) growth mode. All samples were grown at a temperature of $450^{\circ} \mathrm{C}$, except the $80 \mathrm{~nm}$ thick layer in compression which was grown at $525^{\circ} \mathrm{C}$.

The structural properties of the epitaxial layers were investigated using high resolution x-ray diffractometry. For each layer, the residual strain, $\epsilon$, and the indium composition were obtained from symmetrical and asymmetrical measurements. A relaxation coefficient, $R,{ }^{14}$ given by $R=(f-\epsilon) / f$ was also derived for each sample. $R$ represents the extent of strain relief $(f-\epsilon)$ normalized to the lattice mismatch, $f$. 
TABLE I. Composition, $x$, lattice mismatch, $f$, residual strain, $\epsilon$, relaxation coefficient, $R$, thickness, $h$, and normalized thickness, $h / h_{c}$ for samples in tension and in compression.

\begin{tabular}{clccrrr}
\hline \hline Sample & $x$ & \multicolumn{1}{c}{$f$} & $\epsilon$ & $R(\%)$ & $h(\mathrm{~nm})$ & $h / h_{c}$ \\
\hline$A$ & 0.42 & $-7.7 \times 10^{-3}$ & $-7.4 \times 10^{-3}$ & 3.5 & 200 & 11 \\
$B$ & 0.405 & $-8.7 \times 10^{-3}$ & $-6.6 \times 10^{-3}$ & 24.5 & 500 & 33 \\
$C$ & 0.405 & $-8.7 \times 10^{-3}$ & $-5.8 \times 10^{-3}$ & 33.5 & 700 & 46 \\
$D$ & 0.41 & $-8.4 \times 10^{-3}$ & $-3.7 \times 10^{-3}$ & 55.5 & 1000 & 60 \\
$E$ & 0.675 & $9.8 \times 10^{-3}$ & $9.2 \times 10^{-3}$ & 6.5 & 80 & 6 \\
$F$ & 0.675 & $9.8 \times 10^{-3}$ & $3.2 \times 10^{-3}$ & 67 & 520 & 39 \\
\hline \hline
\end{tabular}

This relaxation coefficient is the average of two relaxation coefficient, $R_{[011]}$ and $R_{[0-11]}$ measured along each $\langle 011\rangle$ inplane directions.

The results obtained from x-ray diffraction experiments are reported in Table I, where $x$ is the indium composition, $h$ is the nominal layer thickness and $h_{c}$ the corresponding critical layer thickness. ${ }^{15}$ The residual strain behavior of our samples is better illustrated in Fig. 1, where the relaxation coefficient $R$ is plotted as a function of $h / h_{c}$. Our results clearly indicate that layers grown under tensile stress have a larger residual strain. In particular, samples $C$ and $F$ have about the same value of $h / h_{c}$, but the tensile residual strain is about twice as large as the compressive one. This is a strong argument not only to confirm the existence of two strain relief mechanisms, but also to establish that each mechanism involves a different type of defect. However, differences in thermal expansion coefficients between epilayer and substrate can lead to an additional strain during the postgrowth cooling process. If the substrate has a lower thermal expansion coefficient, as in the InGaAs/InP system, it imposes a tensile stress on the film upon contraction. Consequently, the relaxation coefficient increases for layers with a positive mismatch and decreases for layers with a negative mismatch. This has been already proposed by Clark et al. ${ }^{16}$ and is in qualitative agreement with our observations. We have derived the magnitude of this effect using data from Berstein and Beals. ${ }^{17}$ Assuming that the thermal stress is entirely accommodated by elastic strain, the values of the relaxation coefficients induced only by the lattice mismatch in samples $A, B, C$, and $D$ are now increased to $8.5 \%, 29.5 \%$,

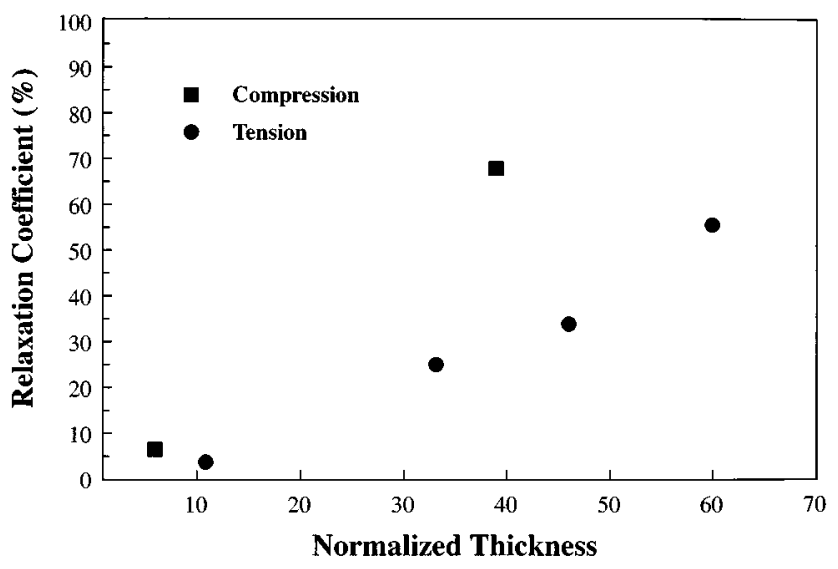

FIG. 1. Variation of the relaxation coefficient as a function of the normalized thickness $h / h_{c}$, for layers under tension (full circle) and under compression (square).
$38.5 \%$, and $60.5 \%$, respectively, and for samples $E$ and $F$ they are reduced to $2.5 \%$ and $63 \%$, respectively. Consequently, by comparing samples $C$ and $F$, the thermal stress cannot account entirely for the differences observed in residual strain.

In a tensile strain system, a perfect $60^{\circ}$ type dislocation can dissociate into two partial dislocations of $90^{\circ}$ and $30^{\circ}$ type, respectively, as shown by Maree et al. ${ }^{18}$ for the $\mathrm{GaP} / \mathrm{Si}$ system. In addition, for the InGaAs/InP system, Hull et al. ${ }^{10}$ have shown that, for tensile strain larger than $6 \times 10^{-3}$, the excess stress on a $90^{\circ}$ partial dislocation is greater than that on the undissociated $60^{\circ}$ total. This dissociation mechanism could partially explain the larger residual strain measured in our samples under tension since the stress-releasing component of the Burger's vector associated with a $90^{\circ}$ partial dislocation is $2 / 3$ that of a $60^{\circ}$ total. It should be pointed out, however, that Hull et al. have also measured by TEM a density of dislocations which is two orders of magnitude larger in the tensile case than in the compressive case for a lattice mismatch of about $1 \%$ and different layer thicknesses, leading to a larger relaxation in the tensile regime. If the same situation prevails in our samples, it is unlikely that $90^{\circ}$ partial dislocations are the main stress releasing defects, despite the reduction of their strain relief efficiency.

The gliding velocity, $V$, of a dislocation is an important parameter which can influence the relaxation process. This parameter depends upon the nature of the material and is expected to change with the indium composition. Alexander and Haasen ${ }^{19}$ have proposed the following expression for $V$ :

$$
V=B \tau_{\text {eff }} \exp (-U / k T),
$$

where $B$ is a constant, $\tau_{\text {eff }}$ is the effective stress acting on a dislocation, $T$ is the temperature and $U$ is a material dependent activation energy. Using data from Sumino and Yonenaga, ${ }^{20}$ the dislocation gliding velocity for an $\mathrm{In}_{0.65} \mathrm{Ga}_{0.35} \mathrm{As}$ layer is estimated to be 3 times larger than that of a $\operatorname{In}_{0.42} \mathrm{Ga}_{0.58} \mathrm{As}$ layer for both $\alpha$ and $\beta$ dislocations at a growth temperature of $450{ }^{\circ} \mathrm{C}$. Although it is difficult to predict exactly the effect on the relaxation coefficient, this difference in dislocation gliding velocity is expected to favor strain relief in layers under compression. The relaxation is expected to proceed faster which might lead to a smaller residual strain in qualitative agreement with our data.

Finally, the asymmetry in strain relaxation is different from one set of samples to the other. Samples in compression exhibit a mostly isotropic strain relief along $\langle 011\rangle$ directions, as expected from layers grown on (100) on-orientation substrates. ${ }^{21}$ On the other hand, samples in tension show a large asymmetry. First, it should be pointed out that this is in 


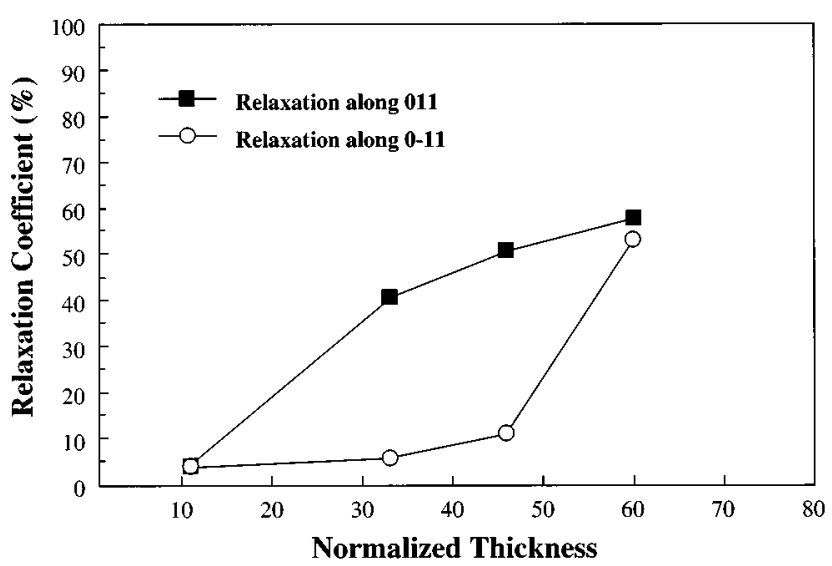

FIG. 2. Variation of the relaxation coefficient in each $\langle 011\rangle$ in-plane direction as a function of the normalized thickness $h / h_{c}$. The lines are intended to be a guide for the eyes.

contrast with results obtained in the InAlSb/InSb tensile system, ${ }^{7}$ where isotropic relaxation was observed. Our results are illustrated in Fig. 2. The relaxation is larger in the [011] direction as expected from the alignment of the line defects along $[0-11]$ observed with atomic force microscopy. This asymmetry first increases then decreases with increasing layer thickness. Figure 2 shows also a striking difference between the two orientations. Along the [011] direction the relaxation coefficient is roughly linear with respect to $h / h_{c}$, however, along the $[0-11]$ direction, no significant relaxation is measured up to about 45 times the critical layer thickness, after which a steep increase is observed. Therefore, according to Fig. 2, stress releasing defects are more difficult to generate along the [011] direction in tensile strain samples. This delay in strain relief is an important factor in explaining the large overall residual strain measured in this study. Also, this might be an indication that defects of different type are involved in each direction. This assumption is in agreement with AFM experiments where microcracks have been observed mostly in the [011] direction. ${ }^{13}$ Moreover, the critical layer thickness for the formation of cracks in layers under tension, as proposed by Matthews and Klokholm $^{22}$ is about 7 times larger than the critical layer thickness for the formation of dislocations in equivalent layers under compression, leading to a delayed relaxation along that direction.
In summary, we have measured the structural properties of InGaAs layers grown in tension on $\operatorname{InP}(100)$ substrates. We have shown that the residual strain and the asymmetry in strain relaxation are larger in tensile strained layers compared to the compressive case. The larger residual strain can be explained by a reduced dislocation glide velocity due to a lower indium content in tensile strained InGaAs layers. Dissociation of perfect $60^{\circ}$ type dislocations into $90^{\circ}$ and $30^{\circ}$ partials is also in agreement with the difference observed in our samples under tensile strain. The asymmetry in strain relaxation observed for tensile strained InGaAs layers show two different behaviors in the formation of defects along $\langle 011\rangle$ in-plane directions. This can be explained by the existence of microcracks observed only in the [011] direction.

${ }^{1}$ A. V. Drigo, Y. Aydinli, A. Carnera, F. Genova, C. Rigo, C. Ferrari, P. Franzosi, and G. Salviati, J. Appl. Phys. 66, 1975 (1989).

${ }^{2}$ D. J. Dunstan, P. Kidd, L. K. Howard, and R. H. Dixon, Appl. Phys. Lett. 59, 3390 (1991).

${ }^{3}$ V. Krishnamoorthy, Y. W. Lin, L. Calhoun, H. L. Liu, and R. M. Park, Appl. Phys. Lett. 61, 2680 (1992).

${ }^{4}$ D. I. Westwood and D. A. Woolf, J. Appl. Phys. 73, 1187 (1993).

${ }^{5}$ C. R. Wie, J. Appl. Phys. 65, 2267 (1989)

${ }^{6}$ G. J. Whaley and P. I. Cohen, Appl. Phys. Lett. 57, 144 (1990).

${ }^{7}$ P. Maigné, D. J. Lockwood, C. Dharma-wardana, and J. B. Webb, J. Appl. Phys. 77, 1466 (1995).

${ }^{8}$ T. Tsuchiya, T. Taniwatari, M. Komori, R. Tsuneta, and H. Kakikayashi, Jpn. J. Appl. Phys. 33, 230 (1994).

${ }^{9}$ M. Gendry, V. Drouot, C. Santinelli, G. Hollinger, C. Miossi, and M. Pitaval, J. Vac. Sci. Technol. B 10, 1829 (1992).

${ }^{10}$ R. Hull, R. A. Logan, B. E. Weir, and J. M. Vandenberg, Appl. Phys. Lett. 63, 1504 (1993).

${ }^{11}$ G. Wagner and P. Paufler, Phys. Status Solidi A 138, 389 (1993).

${ }^{12}$ M. Gendry, L. Porte, G. Hollinger, J. L. Loubet, C. Miossi, and M. Pitaval, J. Appl. Phys. 78, 3138 (1995).

${ }^{13}$ M. Gendry and G. Hollinger, in Proceedings of the First International Conference on Semiconductor Heteroepitaxy (to be published).

${ }^{14}$ B. R. Bennett and J. A. del Alamo, Appl. Phys. Lett. 58, 2978 (1991).

${ }^{15}$ J. W. Matthews and A. E. Blakeslee, J. Cryst. Growth 32, 265 (1976).

${ }^{16}$ S. A. Clark, J. E. Macdonald, D. I. Westwood, and R. H. Williams, J. Cryst. Growth 121, 743 (1992).

${ }^{17}$ L. Berstein and R. J. Beals, J. Appl. Phys. 32, 122 (1961).

${ }^{18}$ P. J. Marée, J. C. Barbour, J. F. van der Veen, K. L. Kavanagh, C. W. T. Bulle-Lieuwa, and M. P. A. Viegers, J. Appl. Phys. 62, 4413 (1987).

${ }^{19}$ H. Alexander and P. Haasen, in Solid State Physics (Academic, New York, 1968), Vol. 22.

${ }^{20} \mathrm{~K}$. Sumino and I. Yonenaga, in Proceedings of the Seventh Semiinsulating III-V Materials Conference, edited by C. J. Miner, W. Ford, and E. R. Weber (Institute of Physics, Bristol, 1992), p. 29.

${ }^{21}$ R. S. Goldman, H. H. Wieder, and K. L. Kavanagh, Appl. Phys. Lett. 67, 344 (1995).

${ }^{22}$ J. W. Matthews and E. Klokholm, Mater. Res. Bull. 7, 213 (1972). 